\title{
AN UNUSUAL CAUSE OF PERSISTENT PLEURAL EFFUSION IN A PATIENT WITH CHRONIC PANCREATITIS
}

Parvathi M11, Kishore Kalya Vyasaraja², Nagaraja Bada Sharanappa ${ }^{3}$

${ }^{1}$ Senior Resident, Department of General Medicine, Bangalore Medical College and Research Institute.

${ }_{2}^{2}$ Post Graduate, Department of General Medicine, Bangalore Medical College and Research Institute.

${ }^{3}$ Professor, Department of General Medicine, Bangalore Medical College and Research Institute.

\section{ABSTRACT}

\section{BACKGROUND}

Persistent pleural effusions pose a diagnostic challenge and need extensive workup to come to a conclusion. Pancreaticopleural Fistula (PPF) is one of the rare causes for persistent massive pleural effusions (1-5). It is seen especially in patients who are alcoholic and with a history of pancreatitis. We report a case of persistent pleural effusion resulting from a pancreatic pse udocyst communicating with pleural cavity in a patient with past history of pancreatitis.

\section{KEYWORDS}

Pancreatitis, Pancreaticopleural Fistula, Pleural Effusion, Amylase.

HOW TO CITE THIS ARTICLE: Parvathi M, Vyasaraja KK, Sharanappa NB. An unusual cause of persistent pleural effusion in a patient with chronic pancreatitis. J. Evolution Med. Dent. Sci. 2016;5(35):2071-2073, DOI: 10.14260/jemds/2016/486

\section{INTRODUCTION}

A 28-year-old male smoker and alcoholic with significant past history of pancreatitis 6 months back presented with history of progressive dyspnoea, dry cough and vague left-sided chest pain since 1 week. However, there was no history of fever, weight loss or loss of appetite.

On examination he had no pallor, cyanosis, clubbing, lymphadenopathy or pedal oedema. His JVP was normal and had no external markers of tuberculosis. His respiratory system examination showed shift of trachea to right side, stony dull note on left chest fields, decreased vocal resonance and vocal fremitus in the same areas and decreased air entry on left side. Other system examination was normal.

A chest X-ray was performed in the Emergency Department, which revealed a massive left pleural effusion. A thoracentesis was performed, fluid which was haemorrhagic in nature, its analysis revealed a exudative fluid with $\mathrm{pH}$ of 7.3 , cell count of 204 with predominant lymphocytes; no atypical cells were seen, protein was of 4.8 gms, ADA was 8 , with amylase $30178 \mathrm{U} \backslash \mathrm{L}$ and lipase $16200 \mathrm{U} / \mathrm{L}$ and culture growing citrobacter freundii. After $24 \mathrm{hrs}$. patient again started developing respiratory distress; repeat radiograph of chest was done which showed reaccumulation of fluid. USG chest was done to assess the pleural effusion, which showed large effusion with floating debris suggesting exudative fluid. Given the rapid reaccumulation of pleural fluid and raised amylase, lipase in pleural fluid, CECT of thorax and abdominal was performed, which revealed a well-defined hypoattenuating collection measuring 30-40 cc, anterior to the tail of pancreas suggestive of a pseudocyst and a large left pleural collection.

Financial or Other, Competing Interest: None.

Submission 13-03-2016, Peer Review 14-04-2016,

Acceptance 18-04-2016, Published 02-05-2016.

Corresponding Author:

Dr. Parvathi $M$

No. $20 / A$,

$6^{\text {th }}$ A Main, $11^{\text {th }}$ Cross,

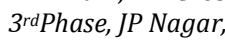

Bangalore-78.

E-mail: drparvathi30@gmail.com

DOI: $10.14260 /$ jemds $/ 2016 / 486$
There was linear enhancing tract noted communicating between the pseudocyst and left pleural cavity via the aortic aperture in the diaphragm. Possibility of pancreaticopleural fistula was suggested on CT and this diagnosis was further supported by the clinical and laboratory data.

In view of recurrent massive pleural effusion, an ICD tube was inserted into left pleural cavity and $1,800 \mathrm{~mL}$ of haemorrhagic fluid removed. Surgical gastroenterologist reference was taken and advised conservative management. The drainage tube was removed after 7 days. Repeat chest radiograph was done, which showed no significant pleural collection. Patient was followed on OPD basis for about 6 months and no recurrence of pleural collection noticed.

\section{An Unusual Cause of Persistent Pleural Effusion in a Patient with Chronic Pancreatitis}

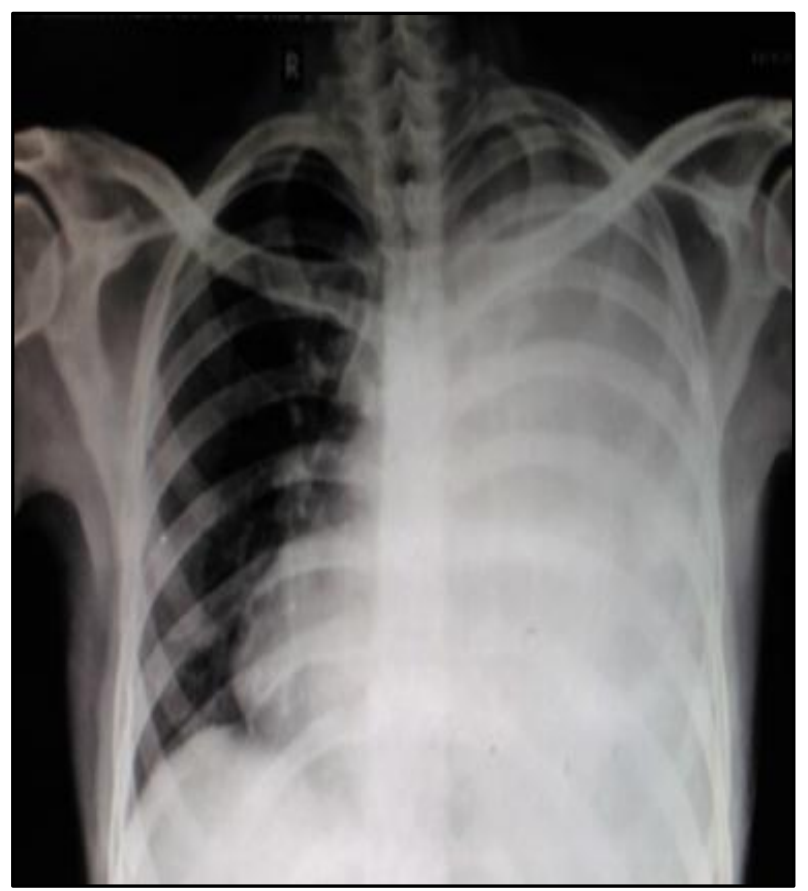

Fig. 1: Chest Radiograph showing Massive Left Pleural Effusion with Mediastinal Shift to Opposite Side 

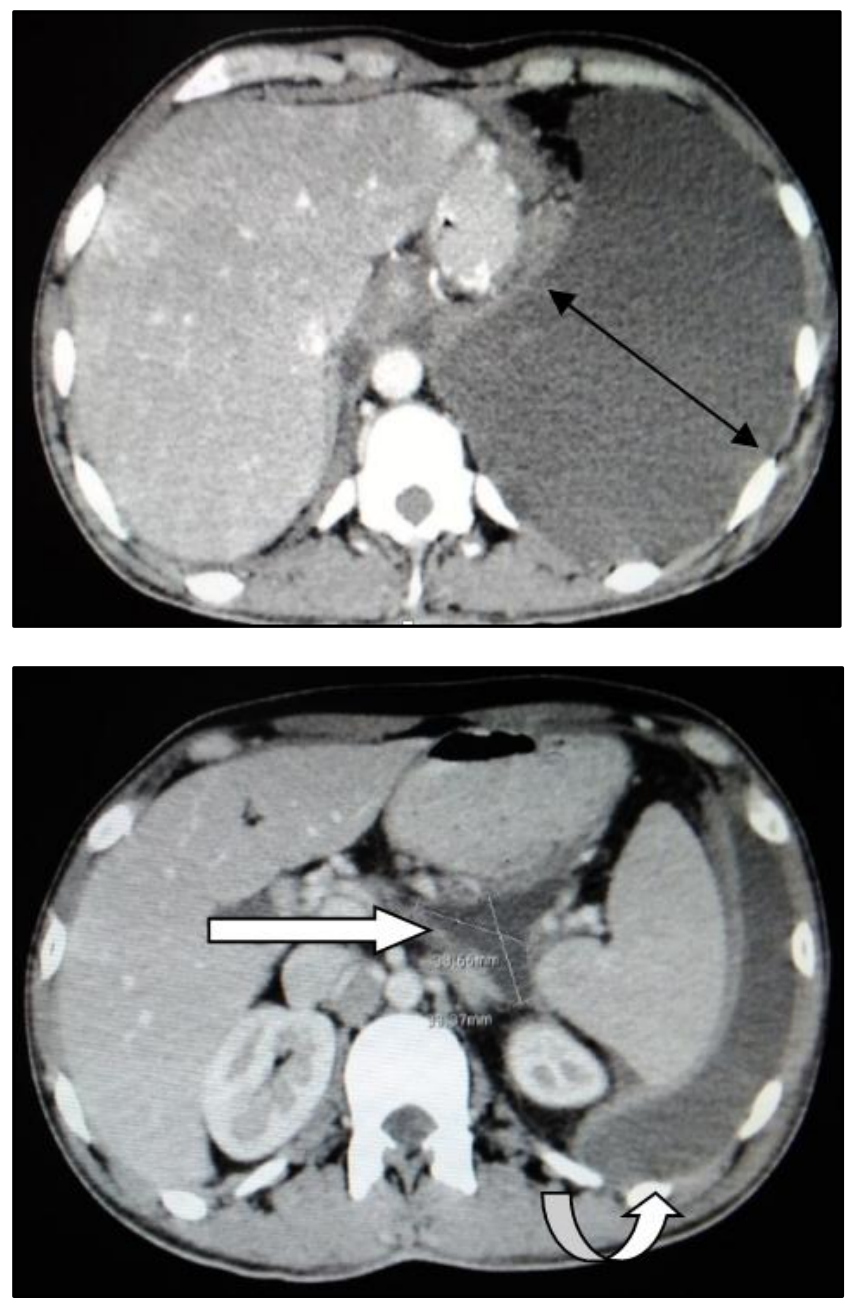

Fig. 2A: Post Contrast CT showing Left Gross Pleural Effusion (Double Arrow) and $2 B$ showing Peri-Pancreatic Pseudocyst (Thick Arrow) with Pleural Effusion (Curved Arrow)

\section{DISCUSSION}

Pancreatico-Pleural Fistula (PPF) is a rare cause of recurrent, large pleural effusions and most commonly results from chronic pancreatitis.(1-5) The usual causes of PPF include trauma, surgical procedures and chronic pancreatitis with duct disruption of any aetiology and the incidence of PPF is about $0.4-4.5 \%$ in cases of pancreatitis.(1) In pancreaticopleural fistula due to pancreatitis, large pleural fluid accumulates due to transdiaphragmatic fistulous tracts which allows a communication between the pseudocyst/peripancreatic collection and the pleural cavity.(6)

The pleuro-pulmonary complications associated with pancreatitis are atelectasis, pneumonitis, adult respiratory distress syndrome and pancreatico-bronchial fistula. Small reactionary pleural effusions develop in $3-17 \%$ of patients with acute pancreatitis. ${ }^{(7,8)}$ In these cases, the pancreatic enzyme activity of the pleural fluid is low and the effusion tends to resolve along with the pancreatitis. These effusions are probably due to sympathetic, chemically induced, diaphragmo-pleural inflammation.

Presence of large recurrent effusions is a hallmark of pancreaticopleural fistula, as in our case it is commonly associated with disruption of the main pancreatic duct and pseudocyst formation. The fistula develops either by direct passage of a pseudocyst through a natural diaphragmatic hiatus (e.g., oesophageal or aortic) or by direct fistulation through the dome of the diaphragm.

The resulting pleural fluid is usually haemorrhagic and amylase-rich with levels above $1000 \mathrm{U} / \mathrm{L}$ as in our case.

The diagnosis of pancreaticopleural fistula is often delayed as the condition is rare with patients presenting with only respiratory symptoms.(1-5) The presence of a large, recurrent pleural effusion may be the only presentation as the pancreatic disease is often asymptomatic and subclinical. It is the amylase activity of the pleural fluid, which is markedly elevated when compared to serum levels. However, few conditions with elevated amylase levels in pleural fluid is known which includes lung adenocarcinoma, female genital cancers, other solid organ cancers, oesophageal rupture. In these conditions, the amylase in pleural fluid is mildly elevated unlike in pancreaticopleural fistula where amylase elevated in thousands in pleural fluid. CECT chest and abdomen is standard modality for demonstrating the fistulous tract and is modality of choice and gold standard for pancreaticopleural fistula. $(9,10)$

Computed Tomography (CT) was able to provide an accurate radiological delineation of the fistula in our patient. ERCP may be necessary to delineate the pancreatic anatomy, but may often fail to demonstrate the fistula. In our case, ERCP/MRCP was not done as the patient showed improvement with conservative therapy.

Initial treatment should be directed towards control of the pleural effusion. Intercostal tube drainage, parenteral nutrition and somatostatin or its analogue octreotide achieved a $48 \%$ fistula closure rate over a $2-3$ week period with conservative management.(9-13)

Failure of medical management of persistent pleural effusion is an indication for intervention including endoscopy and surgery. If the pancreatic duct is intact, ERCP guided transpapillary stenting of the pancreatic can be done.(14,15) Surgical management includes decompression with or without excision of the involved portion of the obstructed pancreas. It is unnecessary to repair a fistulous tract if pancreatic duct obstruction is dealt with adequately. Surgical procedures have an operative mortality of $3-5 \%$ and a good long-term outcome in $80-95 \%$. $^{(16)}$

\section{CONCLUSION}

Pancreaticopleural fistula is a rare cause of recurrent large pleural effusions and we should have a high index of suspicion in patients who are alcoholic and with thoracocentesis yielding a haemorrhagic fluid, rich in amylase. Patients should be further evaluated with imaging to confirm the diagnosis and managed either conservatively, endoscopic procedures or by surgery.

\section{REFERENCES}

1. Ali T, Srinivasan N, Le V, et al. Pancreaticopleural fistula. Pancreas 2009;38(1):e26-e31.

2. Wakefield S, Tutty B, Britton J. Pancreaticopleural fistula: a rare complication of chronic pancreatitis. Postgrad Med J 1996;72(844):115-6.

3. Rockey DC, Cello JP. Pancreaticopleural fistula. Report of 7 patients and review of the literature. Medicine (Baltimore) 1990;69(6):332-44. 
4. Duncan ND, Ramphal PS, Dundas SE, et al. Pancreaticopleural fistula: a rare thoracic complication of pancreatic duct disruption. J Paediatr Surg 2006;41(3):580-2.

5. Uchiyama T, Suzuki T, Adachi A, et al. Pancreatic pleural effusion: case report and review of 113 cases in Japan. Am J Gastroenterol 1992;87(3):387-91.

6. Louie S, McGahan JP, Frey C, et al. Pancreatic pleuropericardial effusions. Fistulous tracts demonstrated by computed tomography. Arch Intern Med 1985;145(7):1231-4.

7. Burgess NA, Moore HE, Williams JO, et al. A review of pancreatico-pleural fistula in pancreatitis and its management. HPB Surg 1992;5(2):79-86.

8. Materne R, Vranckx P, Pauls C, et al. Pancreaticopleural fistula: diagnosis with magnetic resonance pancreatography. Chest 2000;117(3):912-4.

9. Sut $M$, Gray $R$, Ramachandran $M$, et al. Pancreaticopleural fistula: a rare complication of ERCP induced pancreatitis. Ulster Medical Journal 2009;78(3):185-6.
10. Dhebri R, Ferran N. Nonsurgical management of pancreaticopleural fistula. Journal of the Pancreas 2005;6(2):152-61.

11. King JC, Reber HA, Shiraga S, et al. Pancreaticpleural fistula is bestmanaged by early operative intervention. Surgery 2010;147(1):154-9.

12. Vyas S, Gogoi D, Sinha SK, et al. Pancreaticopleural fistula: an unusual complication of pancreatitis diagnosed with magnetic resonance cholangiopan creatography. Journal of the Pancreas 2009;10(6):6713.

13. Safadi BY, Marks JM. Pancreatic-pleural fistula: the role of ERCP in diagnosis and treatment. Gastrointestinal Endoscopy 2000;51(2):213-5.

14. Keyashian K, Buxbaum J. Pleural effusion caused by a pancreatic pleural fistula. Gastrointest Endosc 2012;76:422-4.

15. Koshitani T, Uehara Y, Yasu T, et al. Endoscopic management of pancreaticopleural fistulas: a report of three patients. Endoscopy 2006;38(7):749-51.

16. Olakowski M, Mieczkowska-Palacz H, Olakowska E, etal. Surgical management of pancreaticopleural fistulas. Acta Chir Belg 2009;109(6):735-40. 